\title{
Clarice Lispector no século XXI na Espanha: um diagnóstico dos processos de construção de sua imagem nos campos editorial e acadêmico-científico
}

\author{
Carla Renata LuZ de SouZA \\ Universidade de Santiago de Compostela \\ lispectorluz@gmail.com
}

\section{RESUMEN}

Este trabajo tiene como objetivo dar a conocer cómo se está construyendo la imagen de la escritora brasileña Clarice Lispector en España en el siglo XXI. Mediante la comprensión de que esta imagen es el resultado de la manifestación de una serie de dinámicas que interactúan, elaboraremos un diagnóstico de los campos editorial y académico-científico para indicar cómo su funcionamiento contribuye en ese proceso de construcción.

Palabras clave: Clarice Lispector, España, imagen, siglo XXI.

[Recibido, julio 2013; aprobado, diciembre 2013]

Clarice Lispector in Spain in the 21st century: a diagnosis of the construction processes of her image in the the publishing and academic-scientific fields

\begin{abstract}
This work aims to show how they are building the image of the Brazilian writer Clarice Lispector in Spain in the XXI century. By understanding that this image is the result of the manifestation of a series of dynamic interacting, we will elaborate a diagnosis of the publishing and academic and scientific fields to indicate how their performance contributes to that construction process.
\end{abstract}

Keywords: Clarice Lispector, España, imagen, siglo XXI. 


\section{Introdução}

O biógrafo norte-americano de Clarice Lispector, Benjamin Moser, chama a atenção para a peculiaridade de que uma figura pública que faleceu há pouco mais de 30 anos, que teve sua vida documentada pela mídia e deixou uma extensa correspondência pudesse protagonizar uma rede de informações tão contraditórias, a ponto de várias questões cruciais de sua biografia permanecerem obscuras (2009).

O nome Clarice Lispector já foi considerado um pseudônimo - "nome desagradável, possivelmente um pseudônimo" (Milliet apud Sousa 2000:21); durante anos ninguém parecia saber ao certo onde tinha nascido e qual era sua idade; sua língua nativa era obscura, além disso, seu ceceo e seus erres ásperos e guturais, em função de um problema de língua presa, acentuavam o enigma. Dona de um rosto sedutor e impenetrável, "com olhos amendoados e verdes e as maçãs do rosto salientes" como a descreveu o poeta e intelectual brasileiro Ferreira Gullar (2004:53), ela não deixava ninguém indiferente, como recorda o seu primeiro tradutor para o inglês, Gregory Rabassa, quem comentou ter ficado "pasmo ao encontrar aquela pessoa rara, que era parecida com Marlene Dietrich e escrevia como Virgínia Woolf” (Moser 2009:12).

Filha de imigrantes judeus-ucranianos, Clarice chega ao Brasil em 1920, numa época em que, com evidentes referências das vanguardas europeias, no campo artístico e cultural se vivem novas dinâmicas em relação ao modo de entender a arte e a cultura, sendo Semana de Arte Moderna de São Paulo de 1922 seu maior expoente.

Inaugura sua trajetória como escritora no campo literário brasileiro com o romance Perto do coração selvagem, lançado em 1943, com o qual ganha o Concurso de Melhor Romance do Ano, do jornal Folha Carioca e conquista o Prêmio Melhor Romance de 1943 concedido pela prestigiosa Fundação Graça Aranha. Segundo Santos (1999), a obra premiada representou o início de uma tendência na prosa brasileira em que a exploração de problemas considerados universais substitui as escolhas de temáticas locais. Para Sousa (2000), a partir da afirmação de um não-lugar a experiência literária clariciana implicou uma superação e uma abstração, conseguidas através da desterritorialização, onde a paisagem não será mais as fazendas e sertões nordestinos ou mineiros, e sim o vasto espaço da escrita.

Em meio à repercussão do seu primeiro livro, Clarice Lispector casa com o diplomata brasileiro Maury Gurgel Valente e deixa o país durante 16 anos para acompanhálo em suas viagens diplomáticas. Viveu na Itália, Suiça, Inglaterra e Estados Unidos. Este período fora do país contribuiu para acentuar o mistério em torno da sua figura, bem como gerou dificuldades para a consolidação do seu nome no campo literário brasileiro. Teve que contar com a ajuda de amigos escritores e de suas irmãs para a publicação dos três livros (O lustre, 1946; A cidade sitiada, 1949 e Alguns contos, 1952) que escreveu enquanto esteve ausente do Brasil.

Por outro lado, esse espaço de errância (imigrante no Brasil, estrangeira fora do Brasil) percorrido pela autora, segundo Sousa (2000) irá marcar manifestamente sua escrita, situando-a numa zona de fronteiras marcada pela heterogeneidade, a descontinuidade e a instabilidade, um espaço do entre. O que fará com que sua obra, segundo o mesmo autor, se situe entre a ficção, o ensaio e o poema.

Pouco depois de retornar ao Brasil em 1959, publica o livro de contos Laços de família (1960) pela prestigiada editora carioca Francisco Alves e conquista o Prêmio Carmen Dolores Barbosa, em 1962, com o romance A maçã no escuro, publicado no 
ano anterior na mesma editora, iniciando assim um novo momento da recepção da sua obra no campo literário brasileiro.

Nos seguintes anos publicará alguns dos trabalhos mais consagrados da tradição literária brasileira (A paixão segundo G.H, 1964, A Hora da estrela, 1977), até sua morte no dia 9 de dezembro de 1977.

Atualmente no Brasil, conforme observa Moser (2009), seu rosto ilustra cartõespostais, seu nome concede classe a condomínios de luxo, trechos retirados de sua obra circulam pela internet, seus livros tidos como herméticos enquanto era viva são vendidos em bancas de jornal e basta seu primeiro nome para ser identificada entre brasileiros instruídos.

Traduzida em 14 línguas e em 16 países (Guedes 2012) será através do interesse da crítica, escritora e feminista argelina Hélène Cixous, com a publicação de Vivre l'orange na editora Des femmes, em 1979, que Lispector ganhará projeção internacional. Cixous escreveu amplamente sobre a autora situando-a como o expoente da écriture féminine. Para Almeida a argelina:

constitui uma agente controladora do sistema literário, que atua de dentro dele, visto que ocupa a posição de crítica. Reescreve os textos de Clarice, adequando-os à poética vigente: os estudos de gênero, em especial os estudos da mulher e a crítica literária feminista, enquadrados nos chamados estudos culturais que enfocam, sobretudo, a resistência aos discursos hegemônicos. (1997-1998:42).

Assim, conforme assinala Torres, Clarice Lispector começou a circular na França associada a uma editora especializada em escrita da mulher que detém os direitos de tradução da obra de Clarice Lispector desde 1978:

Des femmes é especializada na publicação de escritoras femininas sem coleção particular no que se refere à literatura brasileira. A editora Des femmes publicou todas as obras de Clarice Lispector em francês desde 1970, sobretudo a partir dos anos 80 [...] (apud Oliveira; Aguiar 2008:39).

Já mais recentemente, no mundo anglófono a recepção do trabalho de Clarice Lispector - e a partir disso, a construção da sua imagem como escritora - recebeu novo impulso com a publicação da celebrada, tanto pela crítica quanto pela mídia, biografia da brasileira elaborada pelo norte-americano Benjamin Moser (Why This World: A Biography of Clarice Lispector. Oxford University Press, 2009). E com a publicação de novas traduções de quatro romances (Perto do Coração Selvagem, A Paixão segundo G.H., Um Sopro de Vida e Água Viva) para o inglês, coordenadas pelo seu biógrafo e publicadas em 2012 pelas editoras New Directions Publishing (USA) e Penguin Classics (Reino Unido).

$\mathrm{Na}$ Alemanha, a editora Schöffling \& Co. acaba de comprar os direitos de publicação da obra de Clarice Lispector, via Programa de Apoio à Traduçao e Publicação de Autores no Exterior, da Fundação Biblioteca Nacional.

E na Espanha, como está sendo recepcionada a obra clariciana? Qual imagem de Clarice Lispector está sendo construída? Marcando a baliza cronológica do século XXI, precisamente o período compreendido entre 2001- maio de 2013, a pergunta da pesquisa que implica este trabalho é: Que imagem de Clarice Lispector está sendo construída na Espanha no século XXI? 
Por entendermos que essa imagem é o resultado da manifestação de uma série de dinâmicas que se interagem, elaboraremos um diagnóstico dos campos editorial e o acadêmico-científico para indicar de que maneira seu funcionamento contribui nesse processo de construção.

No campo editorial, analisaremos os dados que foram recolhidos das pesquisas feitas na hemeroteca da Fundación Cultural Hispano-Brasileña (FCHB), disponível online, cotejando-os e corrigindo-os com os recolhidos na "Base de datos de libros editados en España" do Ministerio de Educación, Cultura y Deporte.

No campo acadêmico-científico analisaremos as informações obtidas a partir da pesquisa nas bases de dados de artigos científicos, ISOC e Dialnet, cotejando-os e corrigindo-os os entre si, bem como de teses recolhidas nos catálogos online das Universidades Públicas da Espanha.

Consideramos os resultados dessas pesquisas, como pequenas peças de um mosaico, que devem ser interligadas para formar um esboço da imagem, que no território espanhol, no século XXI, está sendo formada da escritora brasileira. Não se trata, porém, de um trabalho exaustivo, que ambiciona esgotar o tema, pelo contrário, é um diagnóstico que intenta lançar luz sobre futuras pesquisas.

\section{A Literatura brasileira no Estado Espanhol: limites e desafios}

Diferentes estudos (Calderaro 2009; Arf 2011a) mostram como a literatura brasileira começa a ganhar projeção na Espanha somente no final dos anos 80. Antes disso havia um emaranhado de obras fragmentadas e poucos títulos por autor em diferentes editoras; apesar da dedicação de Juan Valera - que no século XIX, descobre a poesia de Gonçalves Dias - do papel de divulgação da literatura brasileira exercido pelas revistas Electra, Cosmópolis, La Gaceta Literaria e Ínsula no século XX e, sobretudo, a partir de 1962 - com períodos sem publicar - da Revista de Cultura Brasileña que ampliou e aprofundou no estudo, não só da literatura, mas da cultura brasileira (Calderaro 2009). Nessa introdução da literatura brasileira também tiveram um papel relevante pessoas como Ángel Crespo que, além de dirigir a Revista de Cultura Brasileña durante oito anos (1962-1970), traduziu para o espanhol a obra de Guimarães Rosa, Grande Sertão: veredas; Basilio Losada que traduziu várias obras de autores brasileiros, entre elas, Perto do coração selvagem de Clarice Lispector; ou Mario Merlino, que também traduziu a Nélida Piñon, Jorge Amado, Rubem Fonseca e Clarice Lispector.

As transformações políticas e socioeconômicas, o início da internacionalização da economia, as reformulações do conceito de espaço e tempo advindas do desenvolvimento tecnológico, informativo e comunicacional, ocorridas no final da década de 80 e inícios da de 90, afetam o modo de ver e entender as artes no Brasil. De tal modo que a cultura começa a ser considerada uma estrutura valiosa na construção e na difusão da identidade nacional, de modo que se incrementa o investimento em leis e incentivos fiscais, promovendo a estruturação do mercado cultural.

Mesmo assim, atualmente, podemos perceber que o Brasil é ainda tímido na exportação da sua literatura (Villarino Pardo 2012). Apesar da sua diversidade, com exceção de Paulo Coelho e Jorge Amado os escritores brasileiros apenas são conhecidos na Espanha. Conforme Vila Barbosa:

Brasil sigue siendo un actor secundario dentro de nuestra escena cultural. En muchas ocasiones, las traducciones existentes surgen de la insistencia de uno u otro traductor, soñador enamorado del ingenio de los autores brasileños (2012:112). 
Algumas das razões para esse secundarismo, ainda segundo a mesma autora, serão a falta de políticas de exportação brasileira, o espaço pequeno reservado à promoção da literatura brasileira na Espanha e a dificuldade de traduzir para o espanhol as particularidades do português do Brasil.

Recentemente, percebemos a coordenação de esforços no sentido de fomentar as políticas de exportação brasileira. O Ministério da Cultura (MinC) através da Fundação Biblioteca Nacional (FBN) vai investir, até 2020, US\$ 35 milhões em uma ampla política pública de longo prazo que visa ampliar a presença do livro brasileiro no exterior. Esse valor será investido em financiamento de tradução de obras e na divulgação de autores/as brasileiros/as fora do país por meio de participação em eventos de prestígio, programas de residência, apoio a viagens, palestras e encontros (Villarino Pardo 2012).

Uma das principais medidas dessa política é o Programa de Apoio à Tradução e à Publicação de Autores Brasileiros no Exterior, que em 2011 foi remodelado e ampliado $^{1}$, com a orientação de atender todas as propostas que cumpram as exigências do edital e não somente as melhores, como acontecia.

Outra estratégia do MinC-FBN é a intensificação da presença das editoras nacionais nos principais eventos no exterior. Em 2012 o Brasil foi convidado de honra em Bogotá, nos 25 anos desta que é uma das principais feiras de livro da América do Sul. Em 2013 será homenageado, pela segunda vez, pela mais prestigiosa feira do livro do mundo, a de Frankfurt. Em 2014 o país será o destaque principal da Feira do Livro de Bolonha, a mais importante do mercado internacional para a literatura infantil e juvenil. Nessa mesma década será homenageado no Salão do Livro de Paris, na Feira do Livro de Londres e em Nova Iorque, entre outras. Além disso, a Câmara Brasileira do Livro (CBL) participa dos principais eventos da área no mundo, buscando reforçar sua presença nos anos que seguem essas homenagens.

Outro reforço na divulgação da literatura brasileira no exterior é a revista Machado Magazine $^{2}$, editada em parceria entre a FBN e o Instituto Itaú Cultural, com apoio do Itamaraty e da Imprensa Oficial do Estado de São Paulo. Trata-se de uma publicação trimestral em versão digital e impressa com primeiros capítulos e trechos em inglês e castelhano voltada para o mercado internacional e a recepção da literatura brasileira no exterior.

O século XXI, conforme prenunciou Basilio Losada (1999:58), poderia ser o século da literatura brasileira. Porém, a nível internacional, que literatura será essa?

Este é um novo quadro que as instituições brasileiras começam a desenhar para ampliar a presença da literatura brasileira no exterior (Villarino Pardo 2012). É esta pesquisadora (2010) quem se pergunta se hoje, a exemplo da música e do cinema, existe já uma marca que se detecte internacionalmente como 'made in Brazil' para a literatura brasileira ou funciona mais o nome concreto de um escritor ou escritora e não tanto a origem coletiva.

Nomes como Machado de Assis, Guimarães Rosa, Jorge Amado, Paulo Coelho, tão diversos entre si, são considerados literatura brasileira. Mas, o que eles têm de "brasileiro", de "made in Brazil"? Dando a volta no parafuso, não será que internacional-

\footnotetext{
${ }^{1}$ Entre 1991 e 2010, foram concedidas 178 bolsas às editoras estrangeiras para financiar a tradução (o programa oferece até US\$ 8 mil para tradução e também prevê apoio à reedição de obras esgotadas no exterior, tanto para edições impressas como no formato e-book.)

${ }^{2}$ Vid. http://www.machadodeassismagazine.bn.br/index.php
} 
mente já se tem prefixado o que é brasileiro (exotismo, sensualidade, violência), de modo que o que rompe com essa ideia fica fora e funcionam os nomes concretos.

Nesse sentido, o brasilianista alemão Berthold Zilly, na edição de 2010 da Festa Literária Internacional de Paraty (Flip), comenta que existem muitos estereótipos na imagem que se tem do Brasil, como um país exótico, erótico, de cultura popular forte e natureza exuberante e que foi Machado de Assis quem ensinou aos alemães que o Brasil é também um país profundamente urbano (Rodrigues 2010).

A recepção de um/a escritor/a em outro campo literário envolve uma releitura e, portanto, uma construção da imagem desses escritores/as. Por exemplo, Jorge Amado, que para campo literário brasileiro é um subversivo, delator do coronelismo e outras injustiças sociais e políticas no Brasil da sua época, ao ser recepcionado pelo campo literário espanhol, associa-se, ainda que não exclusivamente, ao exotismo e sensualidade das terras brasileiras.

E qual será, na Espanha, a imagem de Clarice Lispector? De que maneira os agentes do sistema literário espanhol, como produtores do sentido e do valor da obra, concorrem na criação da imagem da autora?

\section{Clarice Lispector no mercado editorial}

No seu livro A República Mundial das Letras, a socióloga francesa Pascale Casanova (2001), defende a ideia de que a literatura pode ser considerada em termos de mapas mundiais distribuídos de acordo com a área linguística de cada produção. Nessa configuração, a literatura brasileira pertence à área do português, considerada periférica, excêntrica. Essa perspectiva talvez explique, em parte, o fato de a literatura sulamericana de língua espanhola, ter conseguido muito mais êxito na Europa, fundamentalmente a partir da década de 1960 com o chamado boom latino-americano. Dentro desse mapa linguístico, o espanhol acumula maior capital simbólico em relação ao português. No caso da Espanha, o fato de não ser necessário traduzir é outro diferencial para aqueles textos produzidos na América de fala hispânica.

O Brasil pouco ou nada se beneficiou do boom latino-americano que atribuiu fama a autores como García Márquez ou Vargas Llosa, e permitiu a circulação das suas obras fora dos seus países de origem. Em sua obra Escândalos da tradução, Lawrence Venuti observa:

O boom foi em grande parte um aumento nas traduções das literaturas hispânicas que negligenciou as evoluções brasileiras contemporâneas: entre 1960 e 1979, as editoras britânicas e americanas publicaram 330 traduções do espanhol, mas somente 64 traduções do português brasileiro. (2002:318).

Além disso, conforme salienta a professora Gilda Oswaldo Cruz:

O Brasil não teve a vantagem de contar, como seus vizinhos de continente, com a vigorosa caixa de ressonância que a renascida Espanha dos finais da década de sessenta significou para os países do sul. O empobrecido Portugal imerso, até 1975, na letargia salazarista, não pôde funcionar como porta literária para sua ex-colônia (1988:14).

A descoberta da obra de Clarice Lispector na Espanha foi tardia, chegando duas décadas depois de sua divulgação na França. Conforme dados recolhidos da hemeroteca da Fundación Cultural Hispano Brasileña e cotejados com os recolhidos da Base de datos de libros publicados en España do Ministerio de Educación, Cultura y Deporte, o 
século XXI concentrou 78\% das publicações (incluindo edição e reedição) das traduções da escritora no Estado Espanhol.

A maior parte dessas publicações foi editada em castelhano (72\%), seguidas do catalão (8\%). Ademais, fora das línguas autonômicas do território espanhol, foi publicado um título em português. Nas demais línguas oficiais (galego e euskera) não houve publicação.

A editora Siruela foi responsável por $61 \%$ do total das publicações da escritora. Os cinco livros infantis da autora foram publicados pela editora madrilena Sabina (Coleção Luzazul), em castelhano. Além disso, a editora catalã Cruilla (Coleção El Vaixell de Vapor, Sèrie Blanca) publicou dois em catalão.

Quanto aos/às tradutores/as, Elena Losada Soler foi quem mais traduziu obras de Clarice Lispector, 62\% dos títulos traduzidos no século XXI. Cristina Sáenz de Tejada e Juan García Gayo traduziram duas cada um e compartilharam a tradução de outra.

Além dessas traduções, no século XXI, ainda foram publicadas uma obra de divulgação realizada pela escritora, crítica e tradutora Laura Freixas, intitulada Clarice Lispector, em 2001 pela editora Omega; a biografia Ladrona de rosas (Clarice Lispector: una genialidad insoportable), publicada pela mesma autora em 2010 e editada pela Esfera de los libros; um ensaio escrito pela colombiana Miryam Jimenez Quenguan intitulado Clarice Lispector y María Zambrano: el pensamiento poético de la creación em 2009, pubicado pela editora madrilena Hora y Horas; um outro estudo intitulado Epistemología subversiva: el discurso místico de Teresa de Jesús y Clarice Lispector da canadense Carolina Doreley Coll, publicado em 2006 pela editora Pliegos; além da publicação pelo Servicio de Publicaciones da Universidad Complutense de Madrid (UCM), da tese de doutorado, El discurso narrativo de Clarice Lispector, do professor Antonio Maura, em 2003.

Atualmente todos os romances, novelas, contos e livros infantis de Clarice Lispector foram traduzidos na Espanha para o castelhano, além de alguns títulos em catalão. Além disso, a editora Siruela também vem traduzindo alguns livros de textos jornalísticos e correspondências da autora.

Tanto a editora Siruela quanto a tradução de Elena Losada Soler, por serem a principal editora e a principal tradutora respectivamente, certamente jogam um papel fundamental na construção da imagem de Clarice Lispector do século XXI no território espanhol. Sendo assim, analisaremos o papel desses dois agentes no processo de configuração dessa imagem.

\subsection{Reescrevendo Clarice Lispector: a tradução de Elena Losada Soler}

Lefevere (2007:9) sustenta que "para leitores que não podem checar a tradução com o original, a tradução simplesmente é o original". Desta forma, somente por meio da tradução o texto-fonte amplia as fronteiras e é lido por pessoas de outros países e outras culturas. Ele cunha o termo "reescritura" para contrapô-lo à "escritura" e afirma que os reescritores:

são hoje os responsáveis pela recepção e sobrevivência geral das obras literárias entre leitores não-profissionais, que constituem a grande maioria dos leitores na nossa cultura global, pelo menos na mesma, se não numa extensão maior, que os próprios autores. (Lefevere 2007:9) 
A primeira tradução de uma obra completa de Clarice Lispector foi a francesa feita por Denise-Teresa Moutonnier de Perto do coração selvagem (Près du coeur sauvage,) publicada em 1954, que a autora considerou "escandalosamente ruim" (apud Pereira 1995:2). A tradutora, segundo Pereira (1995) abusou de um excessivo francesismo, a ponto de neutralizar o estilo e a sintaxe da autora.

Na segunda tradução da mesma obra, em 1981, Hubert afirma que, "por ocasião da primeira aparição na França, mais de vinte anos antes, Perto do coração selvagem foi considerado "o livro feminino mais insuportável jamais publicado" (apud Pereira 1995: 2). Também em outras publicações ( $A$ maçã no escuro - Le Biltisseur des ruins, 1970 e A paixão segundo G.H.- La Passion selon G. H. 1978), os tradutores (Violante do Canto e Claude Farny, respectivamente) tenderam a "corrigir" o estilo da autora contrariando a linguagem dos originais.

Sabemos que o tradutor é antes de tudo um leitor. Podemos dizer que é um leitor histórico, uma vez que deixa traços marcados de suas leituras, inscreve sua leitura. Essa leitura é apenas uma entre outras possibilidades de ler um texto, que reflete o estilo e formação do tradutor. Desta forma, a prática da tradução contribuir no processo de valorização de um/a escritor/a, bem como para a sua divulgação.

A tradução literária possui dificuldades específicas, de modo que sua avaliação é um processo complexo. O português do Brasil, segundo Vila Barbosa, "no es una lengua asentada, sino que es rebelde, novedosa, maculada, empapada de otras esencias, urbana y medieval a la vez, imprevisible y creativa" (2012:112). Além do mais, de acordo com Losada, o Brasil "no se ha preocupado de hacer una literatura en serie, con modelos prefabricados, de fácil exportación, con fórmulas rápidamente asimilables" (1999:58). O que dificulta a divulgação e comercialização da literatura brasileira em outras culturas (Vila Barbosa 2012).

Somada às peculiaridades do português brasileiro, a tradução de Clarice Lispector oferece outros desafios, já que:

Los textos 'extraños' de Lispector, que sitúan a la palabra siempre al borde del abismo de la inefabilidad, a veces agramaticales, llenos de anacolutos sintácticos y conceptuales, se entrañan en el propio lenguaje del traductor y le imponen una lucha constante para mantener el máximo posible de fidelidad sin cruzar el umbral que haría incomprensible el texto en la lengua de destino (Losada 2008:14).

A professora titular de Literatura Portuguesa da Universidade de Barcelona, Elena Losada Soler, que venceu o Prêmio de Tradução Giovanni Pontiero 2012 pela tradução do livro Minhas Queridas (2010) de Clarice Lispector, afirma ainda que qualquer tentativa de diminuir a estranheza do texto de Clarice Lispector ou interferência na sua linguagem, situando-se além da substituição dos impossíveis gramaticais, é uma falta de respeito.

Ainda que, conforme ressalta Lefevere (2007), nenhuma reescritura esteja isenta de certa ideologia e de certa poética, Elena Losada, ao contrário das primeiras traduções ao francês, esforça-se por conservar a linguagem clariciana, para preservar a energia do seu mundo ficicional, ativando-a num contexto histórico e cultural específico. Esta ativação implica não somente uma transferência de sentido, mas também uma contrução de significados, portanto, opera na contrução da imagem da autora. 


\subsection{Clarice en rose: a capa da Siruela}

Dos fatores que condicionam ou intervêm no acesso do leitor ao texto, ou seja, os intermediários e mediadores, portanto construtores de imagem, a editora é um fator importante. Uma editora reconhecida no mercado editorial dará aos seus publicados maior visibilidade, ainda que o contrário também aconteça, os grandes nomes da literatura concedem prestígio às editoras.

Outro fator que tem papel importante na mediação com o leitor é o desenho gráfico, já que constitui uma forma de comunicar visualmente um conceito, uma ideia, através de técnicas imagéticas. Ainda que todos os elementos (layout, tipografia, uso das imagens, qualidade de impressão, tipo de papel e o acabamento) contribuem para oferecer uma sensação geral, é a capa que fica com a maior parte desse trabalho.

Os para-textos de um livro têm também um papel fundamental na circulação e recepção de uma obra. Segundo Haslam (2007), a capa de um livro tem duas funções: proteger as páginas e indicar o conteúdo. Em relação ao conteúdo, a capa pretende funcionar como um elemento de sedução para que o livro seja aberto, comprado, como uma promessa feita pela editora, em nome do autor, para o leitor.

Dos quinze livros publicados pela editora Siruela de Clarice Lispector, treze levam na capa a imagem da escritora ${ }^{3}$, seja sentada na cadeira do seu escritório escrevendo, seja um close do seu rosto ou simplesmente diante de sua biblioteca particular, e os outros dois apresentam imagens de mulheres.

Fernando Gaona (F.G), editor da Siruela, cedeu uma entrevista à revista mineira Suplemento literário. Edição especial: Literatura Brasileira na Espanha, onde responde à pergunta da entrevistadora, Alessandra Carvalho (A.C) (2009):

A.C- Em sua opinião, a que tipo de público chegam hoje, efetivamente, as traduções para o castelhano da obra de Clarice Lispector?

F.G- O público principal são mulheres, escritores e pessoas com sólidos hábitos de leitura.

A editora Siruela - fundada pelo aristocrata Jacobo Siruela - é conhecida no mercado editorial espanhol pela qualidade e beleza de suas edições e, nas palavras de Férris (2006): "responden a un intento de explorar la cultura alejado de los usos de la hiperveloz industria editorial de España". De modo que a escolha da capa pela Siruela não será gratuita, será parte de uma estratégia de venda voltada para o seu público, ou seja, as mulheres de gosto refinado.

Se a capa pode funcionar como um pequeno cartaz, que chama para o interior do livro, o que se anuncia, talvez seja isso:

(...) Hoy, nadie duda que la narrativa de Clarice Lispector constituye uno de los testimonios más profundos de nuestro tiempo, un intento, quizá sin esperanza, de expresar las contradicciones, los riquísimos matices, el misterio profundo del alma femenina. (Losada 2008:1112)

Santos (1999) argumenta que Clarice Lispector se encaixa nos padrões de gosto de consumo tanto material, quanto cultural da alta sociedade brasileira. Padrões esses inspirados nos modelos europeus e, compartilhados pela elite brasileira, "nos quais os

\footnotetext{
${ }^{3}$ De acordo com o site da Editora dispobível em: http://www.siruela.com/
} 
ideais de altivez, distinção e elevação são engendrados em linguagem pictórica e integrados ao universo dos bens simbólicos consumíveis" (Milliet 1987:142-143).

Nesse sentido, Debord (2008), alega que o princípio do fetichismo da mercadoria, realiza-se completamente no espetáculo, no qual o mundo sensível é substituído por uma seleção de imagens que existe acima dele, e que, ao mesmo tempo, se faz reconhecer como sensível por excelência.

Não haveria, então, uma fetichização do feminino, tratada de forma refinada, através da evocação da figura da autora?

\section{Clarice Lispector nas revistas científicas espanholas}

\subsection{Processos e critérios da pesquisa}

O primeiro critério de seleção tanto das fontes secundárias de informação, quanto das revistas e artigos científicos recolhidos através destas, foi o de serem produzidos por instituições espanholas, ou em parcerias com estas. As fontes secundárias de informação selecionadas foram as especializadas na área de Ciências Sociais e Humanidades ou que as abrange. Além disso, foram selecionadas pela credibilidade das Instituições produtoras, bem como em função de sua relevância como meio de divulgação do conhecimento na Espanha e a amplitude do número de revistas indexadas.

A partir desses critérios foi selecionada a base de dados da Agencia Estatal Consejo Superior de Investigaciones Científicas (CSIC) - que é a maior instituição pública dedicada à investigação na Espanha e a terceira da Europa, ISOC. Esta base é especializada em Ciências Sociais e Humanidades e possui 2330 publicações indexadas, entre monografias, atas de congressos, informes e fundamentalmente revistas. Foi selecionado também o portal bibliográfico Dialnet, por ser um dos maiores portais bibliográficos de acesso livre e gratuito no âmbito de fala hispânica. Seu acervo possui caráter interdisciplinar, mas com predomínio das revistas de Ciências Sociais, Humanidades e de Jurídicas.

Selecionadas as fontes de informação foi feita uma pesquisa pela palavra-chave "Clarice Lispector" e elaborada uma lista dos artigos recolhidos em cada uma delas. Em seguida, as duas listas foram cotejadas com o propósito de elaborar uma terceira mais completa.

Advertimos que nenhuma nem outra fonte é exaustiva, ou seja, não recolhe toda a produção científica espanhola em Ciências Sociais e Humanidades. Os dados expostos aqui são, portanto, aproximados, em função desta limitação.

As quatro revistas que mais publicaram artigos sobre Clarice Lispector foram organizadas no seguinte gráfico: 


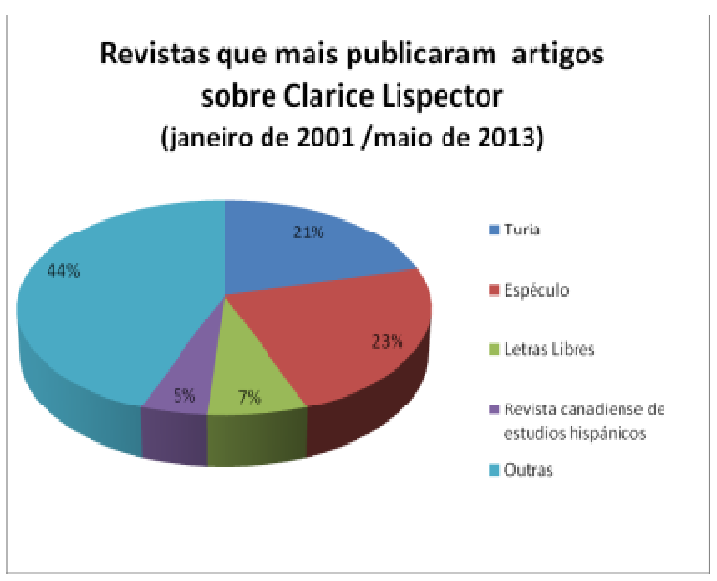

Das quatro revistas que mais publicaram artigos sobre Clarice Lispector no século XXI, somente duas estão avaliadas pelo sistema $\mathrm{RECH}^{4}$ (Revistas Españolas de Ciencias Sociales y Humanidades) que avalia a qualidade editorial das revistas indexadas de acordo com os critérios propostos pela $\mathrm{CNEAI}^{5}$ (Comisión Nacional Evaluadora de la Actividad Investigadora), ANECA ${ }^{6}$ (Agencia Nacional de Evaluación de la calidad y acreditación) e o sistema de informação Latindex ${ }^{7}$.

Segundo o RESH a revista Turia cumpre somente 1 dos 19 critérios indicados pela CNEAI, 1 dos 22 indicados pela ANECA e 12 dos 36 indicados pelo sistema de informação Latindex. A Revista Espéculo, cumpre 6 dos 19 propostos pela CNEAI, 8 dos 22 propostos pela ANECA e 26 dos 36 propostos pelo Latindex. E ainda a revista Turia não está indexada em nenhuma base de dados, e a revista Espéculo em duas, uma nacional, ISOC, e outra internacional, MLA (Modern Linguages Assaciation).

Quanto ao indicador relativo à opinião dos pares, a revista Turia não foi avaliada e Espéculo obteve um 3.14 em um total de 10.

A revista Turia não foi citada nem uma vez durante o quinquênio 2004-2008 e o sistema não aponta valores para a revista Espéculo.

O ICDS (Índice Compuesto de Difusión Secundaria) da revista Turia, calculado pelo sistema de informação MIAR (Matriu d'Informació per a I"Avaluació de Revistes) a partir, especialmente, da difusão internacional da revista em base de dados especializadas - e no caso de não estar indexada em nenhuma base de dados internacional, outros repertórios de âmbito hispânico- mas também dos índices de citações do Institute for Scientific Information (ISI), é de 4.477 sobre 10, e o da Espéculo é 4.255, Letras libres está pontuada em 3.000, e a Revista canadiense de estudios hispánicos em 9.977. Esta é uma publicação da Asociação Canadense de Hispanistas e recebe o apoio do Social Sciences and Humanities Research Council of Canada / Conseil de recherches en sciences humaines du Canada e da Agência

\footnotetext{
4 Para conhecer os critérios de avaliação que oferece e integra o sistema RESH, consultar: http://epuc.cchs.csic.es/resh/como_confeccionado

${ }_{5}^{5}$ Consultar: http://epuc.cchs.csic.es/resh/sites/default/files/CNEAI.pdf

${ }^{6}$ Consultar: http://epuc.cchs.csic.es/resh/sites/default/files/ANECA.pdf

${ }^{7}$ Consultar: http://epuc.cchs.csic.es/resh/sites/default/files/Latindex.pdf
} 
Espanhola de Cooperação Internacional (DRGCC), do Ministerio de Asuntos Exteriores de España. Os artigos são publicados em qualquer língua hispânica, bem como em francês e inglês. Mueller (1999) afirma que as revistas científicas publicadas pelos países que não têm o inglês (mas também os que não estão na fronteira do desenvolvimento da ciência) como língua nacional, não têm o conceito de uma revista de primeira linha e, em geral, não conseguem entrar no círculo de publicações regularmente analisadas pelos prestigiosos índices de citação. Fato que poderia justificar a alta classificação dessa revista em detrimento das outras citadas.

Outro instrumento de medida utilizado pela área de Ciências Sociais e Humanidades na Espanha é o CIRC (Clasificación Integrada de Revistas Científicas) que classifica as revistas científicas em função da qualidade proposta pelas agências de avaliação espanholas CNEAI e ANECA e pelo seu nível de visibilidade, em grupo A, B, C e D.

A revista Letras Libres não integra o sistema e tanto Turia quanto Espéculo estão classificadas no grupo C. Neste grupo estão incluídas as revistas espanholas de segunda ordem, que são pouco citadas e/ou não cumprem os requisitos de publicação científica. Por outro lado, a Revista Canadiense de Estudios Hispánicos está classificada no Grupo A. Este grupo integra as revistas científicas de maior prestígio que tenham superados processos de avaliação muito exigentes para ingressar em distintas bases de dados como a Science citation index e Social sciences citation index o Arts \& humanities citation index.

As autoras dos artigos, editados nessa revista são canadenses. Um dos artigo, "Clarice Lispector y la economía andrógina de "Agua viva"” foi escrito por Carolina Doreley Coll que, como vimos, também escreveu o livro Espitemología subversiva: el discurso místico de Teresa de Jesús y Clarice Lispector em 2006 publicado pela editora madrilena Pliegos. E, Marianella Collette, que escreveu "El reconocimiento de la identidad corporal femenina en 'La pasión según G. H.' de Clarice Lispector”, que originalmente foi apresentado no Forth International Colloquium of the Nortel Professorship: Understanding Literary Culture in Latin America, Spain and Portugal.

O restante das revistas, que somadas representam $44 \%$ da produção sobre Clarice Lispector no século XXI, apresentam a seguinte classificação:

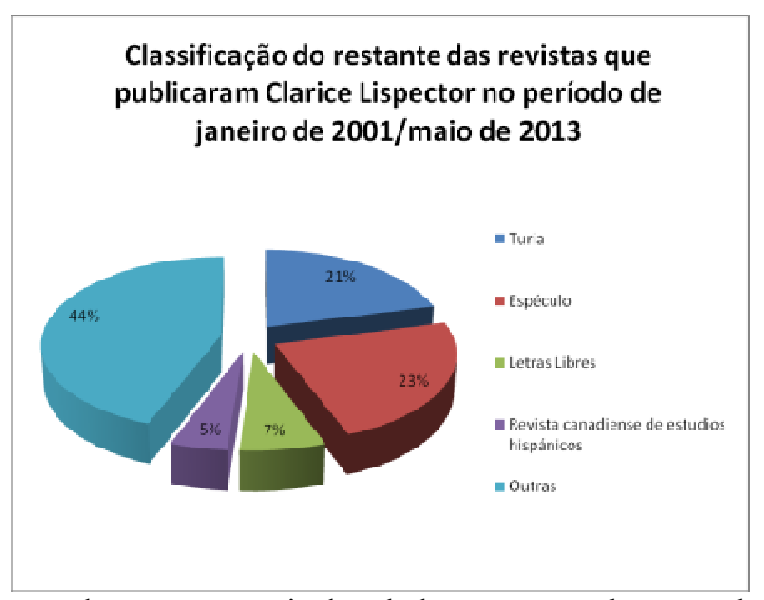

Como podemos observar, a partir dos dados apresentados, que de um modo geral, as publicações sobre Clarice Lispector no período de janeiro de 2001 a maio de 2013 
não estão bem avaliadas pelos sistemas de avaliação espanhóis estudados nesse trabalho.

Como divulgador do conhecimento, a revista científica desempenha um papel importante para a visibilidade, tanto dos seus autores e editores, quanto para a própria temática que lança à luz, uma vez que um assunto que ganhe espaço em revistas de prestígio tende a ter maior impacto. $\mathrm{O} / \mathrm{a}$ cientista, como agente delegado a produzir um tipo de conhecimento específico, exerce uma prática social legitimada e reconhecida como tal. A construção do nome atribui o capital simbólico, sendo esse caracterizado pela posição do agente na estrutura de distribuição do capital científico e como ele é percebido pelos outros pares, igualmente dotados de esquemas de percepção e de apreciação para agirem nesse espaço. Portanto, com pouco capital simbólico, os artigos científicos analisados estão dotados de pouco reconhecimento e prestígio pelo sistema de comunicação e divulgação científico espanhol.

\subsection{Dos/as autores/as}

Dos 43 artigos recolhidos nesta pesquisa, 13 produzidos por espanhóis/nholas, dos quais somente um, Antonio Maura, que foi coordernador da Cátedra de Estudios Brasileños de la Universidad Complutense de Madrid, publicou mais de um artigo ao longo do período que abrange essa pesquisa: "Las moradas de la pasión. (Paralelismos entre La pasión según G.H., de Clarice Lispector y Las moradas, de Teresa de Jesús)" incluído nos Cuadernos para investigación de la literatura hispánica e “Por qué seguiremos leyendo a Clarice Lispector en el siglo XXI?" na revista Turia. Além disso, defendeu em 1997 uma Tese de Doutoramento na Universidad Complutense de Madrid (Departamento de Filología Románica, orientada pela doutora Eugenia Popeanga Chelaru), que ganhou em 2003 uma versão em CD-ROM e foi distribuída pelo Servicio de Publicaciones de la Universidad Complutense de Madrid, intitulada El discurso narrativo de Clarice Lispector.

Também a doutora - com Tese sobre Clarice Lispector - Augustina García Manzano, que publicou o artigo "El universo de la comparación en Clarice Lispector" na revista Estudios portugueses: revista de filología portuguesa, da Universidad de Salamanca, aprofundou um pouco mais no universo clariciano.

Por último, citamos o trabalho do tradutor Mario Merlino, que além da publicação do artigo "Ese cuerpo que aún no hemos comido" na revista Turia, traduziu para o castelhano Um sopro de vida, pulsações, pela editora Siruela, bem como o da escritora e tradutora Cristina Peri Rossi que publicou o artigo "Clarice Lispector o la introspección” na revista Turia e colaborou na tradução de Cuentos reunidos.

Além dos artigos científicos, destacamos as teses de doutoramento sobre Clarice Lispector produzidas nesse período. Pesquisando nos catálogos online das Universidades públicas da Espanha encontramos seis teses. Umas delas é a já citada tese defendida pelo doutor Antônio Maura em 1997, El discurso narrativo de Clarice Lispector, que incluímos no intervalo de tempo desta pesquisa porque foi revista e publicada em 2003.

Em 2007 sob a direção da professora doutora Meri Torras, María Fernanda Álvarez Pérez defende a tese intitulada Cuerpos Liminales, identidades diferidas: La des/construcción de Ken Bugul, EK y Lucrécia Neves na Universitat Autónoma de Barcelona. Em 2008 são defendidas as teses La urgencia creativa para el nuevo milenio: la antropofanía del fragmento en "Un Soplo de Vida" de Clarice Lispector, da colombiana Myriam Jiménez Quenguan, sob a direção da doutora Ana María Leyra Soriano, na 
Universidad Complutense de Madrid; La náusea contemporânea en Clarice Lispector defendida por Carolina Hernández Terrazas, dirigida pela professora doutora Elena Losada Loser, na Universitat de Barcelona e Espais Incorporats, llocs identitaris: Recorreguts per A cidade sitiada, de Clarice Lispector defendida por Mireia Calafell i Obiol, sob a direção das doutoras Meri Torras e Begonya Sáez. Já em 2009, Augustina García Manzano defende a Tese Morder estrellas: el misticismo de Clarice Lispector, na Universidad de Salamanca dirigida pelo doutor Ángel Marcos de Dios.

As teses elaboradas no século XXI sobre Clarice Lispector tratam, entre outros, temas como Filosofia, Existencialismo-Náusea, Epistemologia; Misticismo, Judaísmo; Linguagem; Identidade; Corpo-Corporalidade; Espaço Urbano, e uma revisão da vida e da fortuna crítica da autora. Fronteiriça e polissêmica, a escrita clariciana serve a diversas interpretações. As perspectivas de análise utilizadas na abordagem da sua obra têm sido as mais variadas, tomados da filosofia, da religião, do estruturalismo, do pósestruturalismo, da psicanálise, das teorias feministas, da autobiografia, e muitas outras linhas teóricas. Em conjunto, as teses não apontam para uma tendência interpretativa, como é caso da Clarice da escrita feminina da França de Cixous, mas sim indicam uma Clarice múltipla.

\subsection{Língua de publicação e temas dos artigos}

A língua predominante dos artigos científicos sobre Clarice Lispector publicados na Espanha no XXI é o castelhano com $74 \%$ da produção, seguido do português $24 \%$ e $2 \%$ galego. Nas demais línguas do Estado Espanhol (valenciano e euskera) não foram publicados nenhum artigo durante o período de tempo abrangido por esta pesquisa. A presença do português pode ser explicada pelo fato de algumas revistas (Espéculo, por exemplo) publicarem em português.

O artigo científico quando publicado em uma revista, geralmente, vem acompanhado por um resumo em duas línguas e pela seleção de algumas palavras, que representam o conteúdo do texto, chamadas de palavras-chave. Para fazer o levantamento dos temas tratados nos artigos científicos sobre Clarice Lispector, fez-se uso dessas palavras-chaves e do resumo do texto. Houve casos de artigos, nove ao total, que não foi possível acessá-los. Neste caso não foram criadas palavras-chave por ser considerado muito abstrato trabalhar apenas com os títulos. Optou-se, assim, por ignorá-los, de modo que as palavras-chave que serão manejadas pertencem aos trinta e quatro artigos acessados. Pela diversidade de palavras-chaves, o que tornaria confusa e pouco prática sua organização, essas foram distribuídas em grupos temáticos de acordo com os temas que mantêm relações. Em termos de porcentagem por grupos temáticos, temos o seguinte gráfico: 


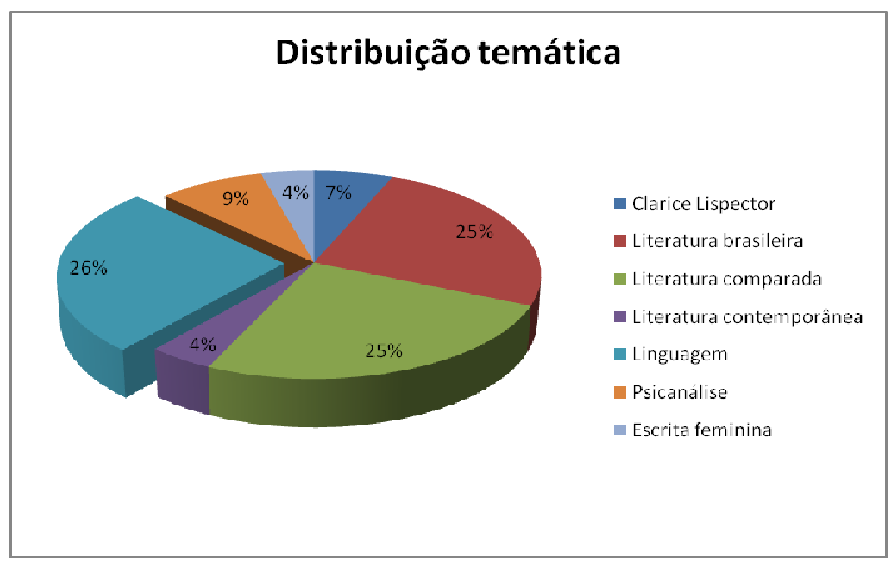

Comumente, a crítica sobre a autora tem se centrado em três pontos principais de análise: a dimensão filosófica e existencial da obra; a construção formal e o estilo narrativo (linguagem) e a questão do feminino (Bailey S/D).

Conforme podemos visualizar o tema que foi mais associado ao universo clariciano foi o da "Linguagem" com $26 \%$ da produção total, seguido de "Literatura brasileira" e "Literatura comparada", concentrando $25 \%$ cada um. O assunto "Psicanálise" concentra 9\% da produção e a figura "Clarice Lispector" 7\%, seguido de "Literatura Contemporânea" e "Escrita feminina" com 4\% cada um. No que concerne à produção de artigos científicos e de Teses, constatamos que existe uma diversidade temática que amplia e enriquece a imagem da escritora.

\section{Conclusões}

Atualmente, o interesse internacional pela produção clariciana vem crescendo como podemos notar com a publicação de quatro novas traduções para o inglês e a compra de direitos para publicação de sua obra feita pela editora alemã Schöffling \& Co \& Co. No entanto, apesar dos recentes esforços no sentido de fomentar as políticas de exportação brasileira com o investimento de US\$ 35 milhões através do Ministério da Cultura (MinC) via Fundação Biblioteca Nacional (FBN) para a ampliação da presença do livro brasileiro no exterior e outras iniciativas, são muitos os desafios que se apresentam ao governo brasileiro no sentido de ampliar e consolidar sua participação no mercado internacional, como por exemplo a continuidade nas políticas culturais para pensar em termos de exportação literária, o incremento de projetos de incentivo à tradução, incremento no patriocínio dos agentes literários, maior valorização e divulgação dos prêmios literários internos (sobretudo, o Prêmio Machado de Assis), investimento na valorização e divulgação do português do Brasil etc.

Por sua vez o escritor gaucho Michel Laub afirma que "se existe algum interesse crescente do mundo pela literatura brasileira, provavelmente se deve a fatores extraliterários: crescimento da economia, maior presença do Brasil no mundo, crise europeia" (2012:20). Seguindo essa mesma ideia, Calderaro (2012) diz que o horizonte de expetativa de uma comunidade leitora em relação a uma obra está ligado a fatores literários, mas também extra-literários. Deste modo, afirma que a partir de 2008, o ano de início oficial da crise na Espanha, o avance político e econômico do Brasil veio 
acompanhado de um visível aumento da presença do país na imprensa espanhola (ainda que ele trate especificamente de Madrid). Esse fato fez com que pouco a pouco fosse diminuindo o carácter exótico que se tem do Brasil e eliminando estereótipos, alterando assim o horizonte de expectativa do público leitor espanhol quanto à literatura brasileira. Neste sentido, a estudiosa Luciene Machado Garcia Arf (2011b) afirma que a literatura brasileira anterior à década de 90 era conhecida como muito próxima à oralidade e vinculada a uma realidade sociológica, sendo que será a escritora Clarice Lispector quem vai "alterar o traçado do mapa literário europeu propondo uma nova inserção do Brasil em contexto espanhol" (2011:35). Assim, no entender dessa estudiosa, longe da oralidade e do folclore brasileiro, a obra da autora, baseada na linguagem e nas relações humanas propõe um novo olhar sobre a literatura brasileira. Consideração bastante acertada se somamos ao seu argumento o resultado desse estudo que verificou que os temas mais associados ao universo clariciano estão bastante distanciados de temas folclóricos ou sociológicos, ao contrário, asssociam-se a temas contemporâneos, como linguagem, psicanálise e feminismo. Ainda que as revistas em que foram publicados os artigos sobre a autora, não gozam de prestígio, de acordo com os sistemas avaliativos espanhóis, fato que fragiliza a consolidação da sua imagem.

Percebe-se que é ainda bastante incipiente e difuso o corpo crítico sobre a obra de Clarice Lispector, com poucos ensaios publicados, poucas teses e poucos/as estudiosos/as que poderíamos chamar de especialista. Em geral, os temas desses trabalhos são diversificados, de modo que não vem se consolidando nenhuma linha interpretativa, como vimos que aconteceu na França através da leitura feminista de Cixous. Por outro lado, a prestigiosa editora Siruela, que vem traduzindo sistematicamente sua obra e conta o trabalho premiado da tradutora Elena Losada Soler, promove e faz circular uma imagem que certamente figurará no imaginário dos/as leitores/as espanhóis/nhas de Lispector: uma mulher, sofisticada, que escreve. O problema desta imagem, imagem-fetiche, é que ela se fecha em si mesma e provoca um sufocamento de sentidos ao impor um sentido único ao público.

Portanto, relacionadas as análises dos dados aqui tratados, concluímos, que a imagem de Clarice Lispector, engendrada desde a Espanha no século XXI, é ainda bastante pálida e fragmentada, uma imagem em contrução. Num artigo intitulado "¿Por qué seguiremos leyendo Clarice Lispector en el siglo XXI?" (2001), Antonio Maura situa a escritora entre os escritores/as do futuro, entre aqueles/as que formularam temas que hoje nos inquietam e que teremos que refletir nos próximos anos. Os primeiros passos, já foram dados, as primeiras reflexões já foram feitas, mas serão necessários ainda alguns anos para que as referências aqui indicadas possam se incorporar a novos estudos e esforços no sentido de consolidar a imagem da autora na Espanha.

\section{Bibliografia}

AlmeIDA, Sandra Regina Goulart (1997-1998): “A crítica feminista no âmbito dos estudos culturais: uma interrupção desejada?”. Crop 4/5: 37-47.

ARF, Luciene Machado Garcia (2011a): “A estética brasileira na Espanha: transformações a partir dos anos 80". Raídos 5:27-36.

ARF, Luciene Machado Garcia. (2011b): "Clarice Lispector e a literatura brasileira no mapa europeu”. Revista de Filología Románica 28:147-156. 
BAILEY, Cristina Ferreira Pinto (S/D): "Clarice Lispector e a crítica". $<$ http://www.pitt.edu/ hispan/iili/IntroLispector.pdf>. 22/01/2013.

CALDERARO, Sérgio Massucci (2009): "La literatura brasileña en España a lo largo del tiempo: intentos de divulgación". Espéculo. Revista de estudios literários 43. $<$ http://www.ucm.es/info/especulo/numero43/librasi.html>. 21/12/2012.

CALDERARO, Sérgio Massucci (2012): "La recepción actual de la literatura brasileña en España". Revista de Filología Románica 28:77-95.

CARvalho, Alessandra (2009): "Clarice na Espanha”. Suplemento Literário Edição Especial Literatura Brasileira na Espanha:14-21.

CASANOVA, Pascale (2001): La república mundial de las letras. Trad. Jaime Zulaika. Barcelona: Anagrama.

Debord, Guy (2008): La sociedad del espectáculo. Trad. José Luis Pardo. Valencia: Pre-Texto.

FÉRRIS, Ramón González (2006): "Entrevista con Jocobo Siruela". Letras Libres. $<$ http://letraslibres.com/revista/artes-y-medios/entrevista-con-jacobo-siruela $>$. $17 / 01 / 2013$.

GUEDES, Luciana (2012). “Autores brasileiro publicados na Espanha entre 2000 e 2010", in Regina Dalcastagnè/Leonardo Tonus, Forum dos Estudantes. Anais do IV Simpósio Internacional sobre Literatura Brasileira Contemporânea, Brasília, Universidade de Brasília [no prelo].

Gullar, Ferreira (2004): "Laços de família e outros laços". Cadernos de Literatura brasileira: Clarice Lispector 17/18:44-56.

HASlAM, Andrew (2007): O livro e o designer II . Como criar e produzir livros. São Paulo, SP: Edições Rosari.

LAUB, Michel. (2012): “A ficção nacional no mapa”, in NeTTO, Irinêo Baptista. Jornal da Biblioteca Pública do Paraná 17:23.

LEFEVERE, André (2007): Tradução, reescrita e manipulação da fama literária. Tradução de Claudia Matos Seligmann. Bauru, São Paulo: EDUSC.

LOSADA, Basilio (1999): "Unha literatura para o século XXI. Ensaio de profecía", in $A$ lingua e a literatura galegas nos alicerces do terceiro rexurdimento (1976-2000). Camilo Fernández (coord.), 57-58. Terrassa: Xunta de Galicia - Amics de les Arts i Joventuts musicals de Terrassa - UNED-Terrassa.

LOSADA, Basilio (2008): “Introducción". Cerca del corazón salvaje. 4a ed. Madrid: Siruela.

LOSADA, Elena (2008): "De palabras y espejos. Traducir el misterio", in Jordi Gol (ed.), Atas do Seminário Traduir Clarice Lispector. Barcelona: Paralelo Sur Ediciones, 13-22.

MAURA, Antonio (2001): “¿Por qué seguiremos leyendo Clarice Lipector en el siglo XXI?”. Túria, 152-158.

Milliet, Sérgio (1987): “Diário Crítico". Suplemento Minas Gerais. Belo Horizonte. $19 / 12 / 87$.

Moser, Benjamin (2009): Clarice, uma biografia. São Paulo: Cosac Naify.

Mueller, S. P. M. (1999): "O círculo vicioso que prende os periódicos nacionais". DataGramaZero-Revista de Ciência da Informação. $<$ http://www.dgz.org.br/dez99/Art_04.htm>.12/12/2012. 
OliveIRA, Alexandra Almeida de; AguiAR, Ofir Bergemann de (2008): “O papel de Helénè Cixous na divulgação de Clarice Lispector, à luz da teoria de Lefevere". Tradução \& Comunicação - Revistas Brasileiras de tradutores 17:29-42.

OSWALDO CRUZ, Gilda (1988): “Clarice Lispector, cerca de su corazón salvaje”. Revista Quimera 80:12-18.

PEREIRA, Maria Marta Luas (1995): “Aspectos da recepção de Clarice Lispector na França”. Anuários de Literatura 3:109-125.

RODRIGUES, Sérgio (2010): "Literatura brasileira como (fraco) produto de exportação". Veja. $\quad<$ http://veja.abril.com.br/blog/todoprosa/vida-literaria/literatura-brasileiracomo-fraco-produto-de-exportacao/>. 15/01/2013.

SANTOS, Neli Edite dos (1999). A crítica jornalística sobre Clarice Lispector (19431997). Dissertação de Mestrado, Universidade Estadual de Campinas, Instituto de Estudos da Linguagem.

SousA, Carlos Mendes de (2002): Clarice Lispector: figuras da escrita. Braga: Universidade do Minho-Centro de Estudos Humanístico.

VenUTi, Lawrence (2002): Escândalos da tradução. Trad. Laureano Pelegrin; Lucinéia Marcelino Vilela; Marileide Dias Esqueda; Valéria Biondo. Bauru-SP: EDUSC.

VILA BARBOSA, María Magdalena (2012): "Traducir la literatura brasileña: traición, imposibilidad o milagro. Reflexiones sobre la literatura brasileña en España”. Sendebar 23:111-140.

VILLARINO PARDO, $\mathrm{M}^{\mathrm{a}}$ del Carmen (2010): "Mercados para a literatura brasileira", in Lugares da Lusófonia; org. Petar Petrov, Lisboa: Colibri, 113-124.

VILLARINO PARDO, Ma del Carmen (2012): "Literatura brasileira Contemporânea: o desafio da exportação". Romance Notes 5:151-164.. 